University of Nebraska - Lincoln

DigitalCommons@University of Nebraska - Lincoln

Faculty Publications - Textiles, Merchandising and Fashion Design

Textiles, Merchandising and Fashion Design

Department of

January 1989

\title{
A Comparison of Selected UV Filtering Materials for the Reduction of Fading
}

Patricia Cox Crews

University of Nebraska-Lincoln, pcrews@unl.edu

Follow this and additional works at: https://digitalcommons.unl.edu/textiles_facpub

Part of the Art and Design Commons

Crews, Patricia Cox, "A Comparison of Selected UV Filtering Materials for the Reduction of Fading" (1989). Faculty Publications - Textiles, Merchandising and Fashion Design. 8.

https://digitalcommons.unl.edu/textiles_facpub/8

This Article is brought to you for free and open access by the Textiles, Merchandising and Fashion Design, Department of at DigitalCommons@University of Nebraska - Lincoln. It has been accepted for inclusion in Faculty Publications - Textiles, Merchandising and Fashion Design by an authorized administrator of DigitalCommons@University of Nebraska - Lincoln. 


\title{
A Comparison of Selected UV Filtering MATERIALS FOR THE REDUCTION OF FADING
}

\author{
Patricia Cox Crews*
}

\begin{abstract}
The effectiveness of a UV filtering material of flexible polyester film containing a silver reflective coating was compared to the widely used UV absorbing filters that are almost colorless or have a strong yellow tint. The silvercoated polyester filters caused almost no distortion of color rendition when used as a filter for fluorescent lamps and provided greater protection of artifacts than did the almost colorless filters. The use of UV filters of polyester film with a reflective silver coating is recommended when filters with a strong yellow tint distort color to an objectionable degree and yet greater protection of artifacts is desired than that afforded by almost colorless filters.
\end{abstract}

\section{INTRODUCTION}

A VARIETY OF ULTRAVIOLET FILTERING MATERIALS are in use in museums. However, most filters used over windows, skylights, and fluorescent lights are made of rigid acrylic sheets or flexible films of polyester or acetate that have an ultraviolet absorber dispersed throughout the substrate. Rigid acrylic sheeting is known by a variety of trade names including Plexiglas ${ }^{\circledR}$, Acrylite ${ }^{\circledR}$, and Perspex ${ }^{\circledR}$, whereas flexible polyester film is often described by its tradename Mylar ${ }^{\circledR}$. Both rigid and flexible filters can be obtained in colorless forms as well as forms with varying amounts of a yellow tint ranging from almost colorless to an amber color. The yellowtinted filters vary widely in the amount of visible radiation they absorb. Some with only a light yellow tint remove very little visible radiation, while others with an amber tint absorb much more visible radiation.

Thomson ${ }^{9}$ described the ideal UV absorbing filter as a colorless one that would prevent all UV radiation down to $400 \mathrm{~nm}$ from passing through but would not hinder the passage of any visible light. Crews ${ }^{3}$ suggested that the ideal filter should be modified based on recent research showing that colorless filters afforded some natural dyes no protection against fading. Unlike contemporary synthetic dyes that are faded primarily by ultraviolet radiation, most natural dyes are faded by both ultraviolet and visible radiation, particularly visible light in the violet and blue regions of the electromagnetic spectrum. ${ }^{9}$ Therefore, Crews $^{3}$ suggested that the ideal UV filter should be tinted yellow so that it could prevent the passage of some visible radiation (i.e., violet and blue light) as well as all UV radiation. Yet museum person-

* Department of Textiles, Clothing and Design, University of Nebraska-Lincoln

Copyright (C) 1989 American Institute for Conservation of Historic \& Artistic Works. Reprinted from Journal of the American Institute for Conservation 28 (1989), pp. 117-125, with the permission of the American Institute for Conservation of Historic \& Artistic Works, 1717 K St., NW, Suite 200, Washington, DC 20036; info@aic-faic.org; http://wwwaic-faic.org 
nel sometimes object to yellow-tinted filters because they distort color rendition in exhibit areas.

In an effort to identify a material that would provide the desired level of protection without color distortion, a UV filtering material of flexible polyester film containing a silver reflective coating was examined. Unlike filters with strong yellow tints, it causes almost no distortion of color rendition when used as a filter for fluorescent lamps; however, its effectiveness in reducing the fading of natural dyes was unknown. This research compared the effectiveness of this UV-absorbing material with a silver reflective coating to the widely used UV-absorbing filters with light yellow tints (almost colorless) and the less widely used filters with strong yellow tints (almost amber).

\section{EXPERIMENTAL PROCEDURE}

\section{Fabric}

TWO WOOL FABRICS, one dyed with synthetic blue dyes and one undyed, were purchased for use in the study. The plain weave, worsted wool fabric dyed with synthetic blue dyes was purchased from AATCC (Research Triangle Park, N. C.) It is called Blue Wool Lightfastness Standard L2. Blue Wool Lightfastness Standards are prepared by blending varying proportions of wool dyed with a very fugitive dyestuff, Erio Chrome Azurole B (C.I. 43830) and wool dyed with a fast dyestuff, Indigosol Blue AGG (C.I 73801) so that each higher numbered standard is approximately twice as colorfast as the preceding standard. ${ }^{2}$ Blue Wool Lightfastness Standards L2 and L4 have been used by several researchers in evaluating the effectiveness of UV filters. ${ }^{8}, 10$

The undyed fabric selected for dyeing with natural dyes was a worsted wool flannel, Style 523, purchased from Testfabrics Inc. (Middlesex, N. J.). Wool samples measuring $22.7 \mathrm{~cm} \times 30.5 \mathrm{~cm}$ were scoured individually in $0.5 \%$ AATCC neutral soap solutions (wgt./vol.) at $90^{\circ} \mathrm{C}$ for 30 minutes to remove impurities from manufacturing in preparation for dyeing with natural dyes.

\section{Dyeing Procedures}

Scoured wool samples were dyed in stainless steel, high-temperature LaunderOmeter canisters with 12 dye/mordant combinations following 19th-century procedures. ${ }^{6}$ The natural dyes included cochineal, madder, indigo, fustic, weld, and turmeric. They represent some of the most widely used dyes for red, yellow, and blue colors in American and European textiles prior to the 20th century. ${ }^{1,4,5}$ In addition, their lightfastness properties ranged from fugitive (turmeric) to very stable (indigo). The detailed dying procedures are reported elsewhere. ${ }^{3}$

\section{Ultraviolet Filters and Light Exposure}

Selected for evaluation and comparison in this study were four UV filters:

1. a rigid acrylic sheet with a very light yellow (almost colorless) tint (Plexiglas ${ }^{\circledR}$ UF-3; Rohm and Haas Co., Philadelphia Pa.); 
2. a flexible polyester film with a very light yellow (almost colorless) tint (Solar Screen Co.; Corona, N. Y.);

3. a flexible polyester film with a strong yellow (amber) tint (Solar Screen Co.; Corona, N. Y.);

4. a flexible polyester film constructed by sputter coating one side with pure silver and sandwiching it between another layer of UV-absorbing film (Solar Screen Co.; Corona, N. Y.).

Ultraviolet-visible transmission spectra were made of each filter using a Perkin Elmer $552 \mathrm{UV}$-visible spectrophotometer. The filters were cut to fit in the specimen port. The transmission spectra of each are shown in figure 1 . The rigid and flexible filters with a light yellow tint were substantially colorless transmitting almost all radiation in the visible region of the electromagnetic spectrum but absorbing almost all radiation below $380 \mathrm{~nm}$. The amber filter absorbed strongly in the blue region (450 $\mathrm{nm}$ ) of the visible spectrum and absorbed slightly less UV radiation in the 380-400 nm wavelength than did the substantially colorless filters. The grayish polyester filter with the silver reflective coating, like the almost colorless filters, absorbed almost all radiation below $380 \mathrm{~nm}$, but unlike the substantially colorless materials transmitted only $50 \%$ of the visible radiation. Surprisingly, despite the measurable reduction in transmitted light shown in the spectral curves, the gray filter with the silver coating did not alter color rendition or diminish light levels to a very noticeable extent visually when used as a UV filtering sleeve on a fluorescent lamp in an exhibit case. In fact, it was difficult to distinguish between the areas lighted by lamps with the almost colorless flexible polyester filter and the silver-coated polyester filter.

UV-visible spectra were made of the filters before and after 80, 100, and 600 AATCC fading units (AFUs) of xenon light exposure. An AATCC fading unit is the amount of exposure required to produce 1 CIELAB unit of color difference on Xenon Reference Fabric used for the calibration of water cooled xenon-arc equipment. ${ }^{2}$ Comparison of the spectra before and after 100 AFUs of xenon light exposure showed that none of the spectral curves were significantly altered by that length of exposure. These findings supported earlier work which showed that 80 AFUs of xenon light exposure did not significantly alter the spectral curves of amber and clear flexible polyester filters. ${ }^{3}$ However, 600 AFUs of light exposure significantly altered the flexible filter with the amber tint (see figure 2). The amber filter visibly lightened during exposure, as shown by the increased transmittance of visible radiation near $400 \mathrm{~nm}$ and $500 \mathrm{~nm}$ on its spectral curve. Unlike the flexible amber filter, the flexible polyester filters with the light yellow tint and the silver coating retained their effectiveness as UV filters as well as the rigid acrylic filter throughout 600 AFUs of light exposure.

The UV filters were placed directly over the dyed wool specimens when they were mounted in Atlas SL-8A Fade-Ometer test masks. Specimens were exposed to xenon light for 80 AFUs according to AATCC Test Method 16-E, Colorfastness to Light: Water-Cooled Xenon-Arc Lamp, Continuous Light in an Atlas (Chicago, Ill.) 6,500-watt xenon-arc Weather-Ometer. ${ }^{2}$ Xenon reference fabric was used to control the exposure periods. Borosilicate inner filters and soda lime outer filter glasses were used with the xenon lamp to simulate light exposure behind glass. 

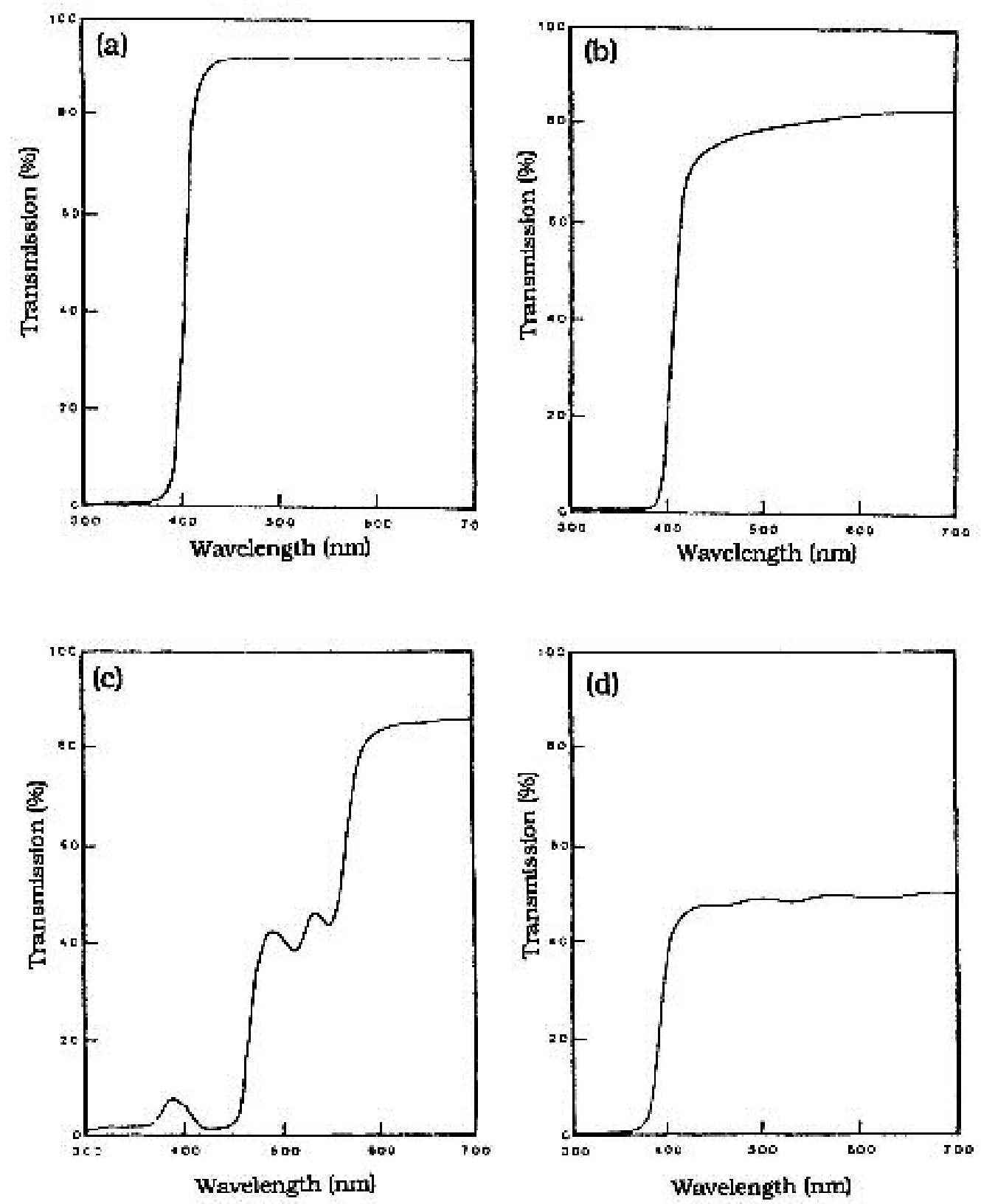

Fig. 1. UV-Visible transmission of UV filtering materials
(a) rigid acrylic (Plexiglas $\left.{ }^{\circledR}\right)$ with a very light yellow tint
(b) flexible polyester with a very light yellow tint
(c) flexible polyester with a strong yellow (amber) tint
(d) flexible polyester with a sputter coating of silver 


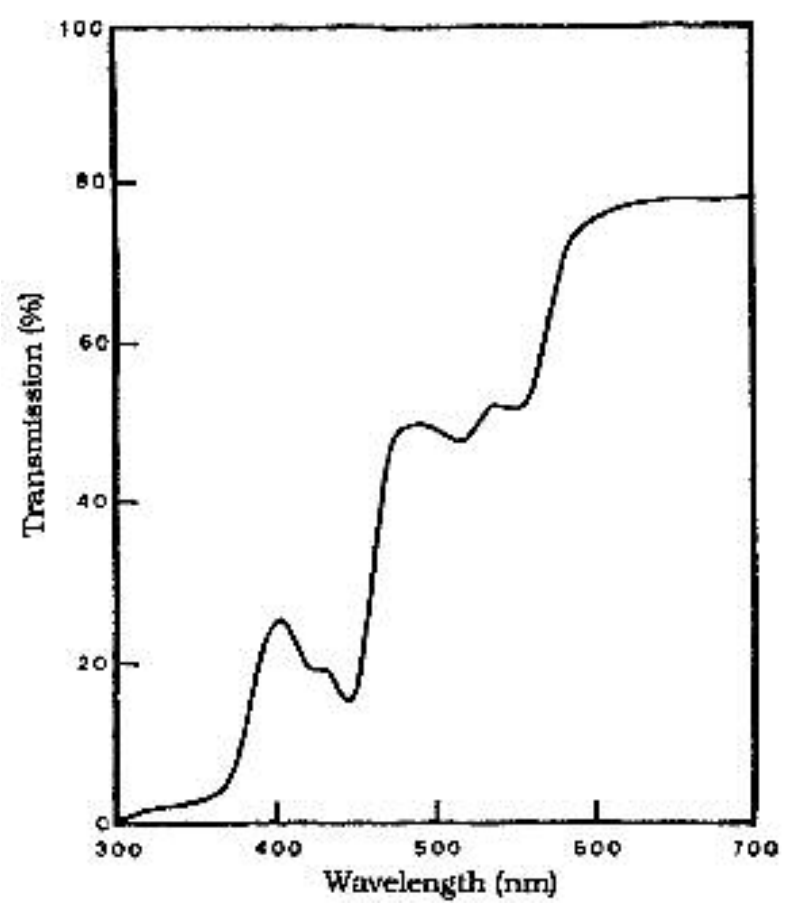

Fig. 2. UV-Visible transmission spectra of amber polyester filter after 600 AFUs of xenon light exposure

\section{Instrumental Color Evaluation}

The dyed specimens were evaluated before and after exposure to 80 AFUs of xenon light with a HunterLab D25-M tristimulus colorimeter using a $2.54 \mathrm{~cm}$ viewing aperture. Total color change that occurred during each exposure period was calculated according to the CIE $1976 \mathrm{~L}^{*} \mathrm{a}^{*} \mathrm{~b}^{*}$ color difference (DE) equation:

$$
\begin{aligned}
\mathrm{DE}=\left[\left(\mathrm{DL}^{*}\right)^{2}\right. & \left.+\left(\mathrm{Da}^{*}\right)^{2}+\left(\mathrm{Db}^{*}\right)^{2}\right] \text { where: } \\
\mathrm{DL}^{*} & =\text { lightness-darkness difference } \\
\mathrm{Da}^{*} & =\text { redness-greenness difference } \\
\mathrm{Db}^{*} & =\text { yellowness-blueness difference }
\end{aligned}
$$

The calculated unit of color difference is abbreviated the CIELAB unit.

\section{Statistical Analysis}

One-way analysis of variance (ANOVA) was used to measure the effect of filter on total color difference after light exposure. If ANOVA procedures showed that type of filter significantly affected total color difference, Fisher's LSD Test was used to determine which UV filter differed significantly from the others. The level of significance was set very conservatively at .01 for the analysis of variance and .05 for Fisher's LSD 
Test because significant differences in the instrumentally measured color differences better correspond with visually perceptible differences at these levels of significance.

\section{RESULTS AND DISCUSSION}

FOUR TYPES OF ULTRAVIOLET FILTERS were evaluated for their effectiveness in reducing fading of wool dyed with selected natural dyes and one synthetic dye. Unprotected wool fabrics dyed with the same dyes and exposed to the xenon-arc lamp served as controls. Color difference (DE) was measured after 80 AFUs of xenon light exposure to determine the comparative effectiveness of the filters in reducing fading or color change.

The mean color difference values for each filter after 80 AFUs of xenon light exposure are given by dye in table 1 along with the results of the Fisher's LSD tests because one-way analysis of variance procedures performed on each dye/mordant combination showed that UV filter was a significant independent variable. All dyes exhibited the least amount of color change when protected by the amber-tinted filter of polyester film; and most dyes were better protected by the silver-coated filter than the filters with the light yellow tints. This result was not surprising since the filter with the reflective silver coating transmitted approximately $50 \%$ of the radiation throughout the visible spectrum, whereas the filters with the light yellow tints transmitted over $80 \%$ of the visible radiation. Only weld (alum) exhibited a significantly greater color difference (DE) after light exposure behind a UV filter (DE = 15.63 with light yellow polyester filter versus $\mathrm{DE}=14.27$ for the control). This unexpected result occurred because the wool control yellowed upon exposure to the UV radiation in the unfiltered light more rapidly than it faded. Natural dyes are faded by both UV and visible radiation, ${ }^{9}$ and wool is yellowed by UV radiation. ${ }^{7}$ The control specimens colored yellow with the weld dye retained more of their yellow color because of the yellowing of the wool substrate whereas the weld-dyed specimens exposed to light behind UV filter underwent no yellowing, only fading caused by the visible radiation. However, this interpretation of the results should not be construed as meaning that it is better to expose objects colored with weld dyes to unfiltered light containing the ultraviolet component.

The percent reduction in mean color difference for each filter is given by dye in table 2. Unlike most natural dyes evaluated, the AATCC Blue Wool L2 dyed with synthetic dyes was protected equally well by all filters (percent reduction in fading was exceptional at approximately $80 \%$ ). Clearly, Blue Wool L2 should not be used in lightfastness tests to compare and/or predict the protective effects of UV filters for museum textiles as has been done in the past. ${ }^{8,10}$ Apparently, Blue Wool L2 is not sensitive to the presence or absence of visible light (at least during the exposure period evaluated in this study) unlike most natural dyes, which are subject to fading by both ultraviolet and visible radiation.

The average percent reduction in fading attributed to the amber-tinted polyester filter was 51\% when the exceptional figure for the Blue Wool L2 was excluded. The average percent reduction in fading attributed to the other filters was $28 \%$ (silvercoated polyester), 16\% (light yellow acrylic), and 15\% (light yellow polyester). These findings support earlier work by Crews, ${ }^{3}$ who found that amber-tinted polyester filters were much more effective than almost colorless polyester filters. 
Table 1

Fisher's LSD Test on Mean Color difference Values for Each Filter after 80 AFUs of Xenon Light Exposure

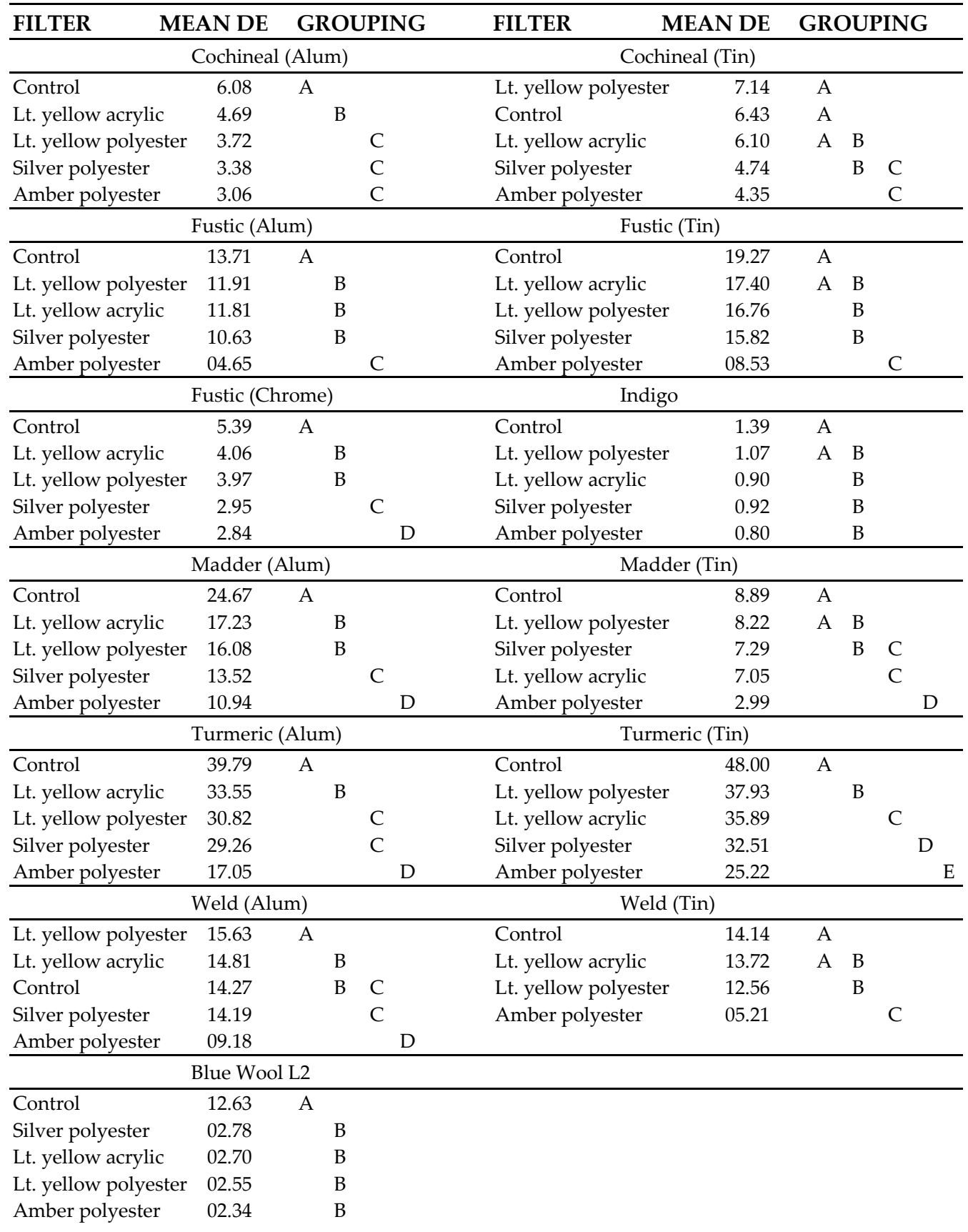


Table 2

\section{Percent Reduction in Fading Attributed to Each Filter after 80 AFUs of Xenon Light Exposure}

\begin{tabular}{lrccc}
\hline & $\begin{array}{c}\text { Light yellow } \\
\text { polyester film }\end{array}$ & $\begin{array}{c}\text { Light yellow } \\
\text { acrylic film }\end{array}$ & $\begin{array}{c}\text { Silver tint } \\
\text { polyester film }\end{array}$ & $\begin{array}{c}\text { Amber tint } \\
\text { polyester film }\end{array}$ \\
\hline Cochineal (Alum) & $39 \%$ & $23 \%$ & $44 \%$ & $50 \%$ \\
Cochineal (Tin) & $0 \%$ & $0 \%$ & $26 \%$ & $32 \%$ \\
Fustic (Alum) & $13 \%$ & $14 \%$ & $22 \%$ & $66 \%$ \\
Fustic (Tin) & $13 \%$ & $0 \%$ & $17 \%$ & $56 \%$ \\
Fustic (Chrome) & $26 \%$ & $25 \%$ & $45 \%$ & $47 \%$ \\
Indigo & $0 \%$ & $35 \%$ & $34 \%$ & $43 \%$ \\
Madder (Alum) & $35 \%$ & $30 \%$ & $45 \%$ & $56 \%$ \\
Madder (Tin) & $0 \%$ & $21 \%$ & $18 \%$ & $66 \%$ \\
Turmeric (Alum) & $22 \%$ & $16 \%$ & $26 \%$ & $57 \%$ \\
Turmeric (Tin) & $21 \%$ & $25 \%$ & $32 \%$ & $47 \%$ \\
Weld (Alum) & $0 \%$ & $0 \%$ & $0 \%$ & $36 \%$ \\
Weld (Tin) & $11 \%$ & $0 \%$ & - & $61 \%$ \\
Blue Wool L-2 & $79 \%$ & $80 \%$ & $81 \%$ & $78 \%$ \\
\hline Average Reduction & \multicolumn{5}{c}{} \\
(excluding Blue Wool L-2) & $15 \%$ & $16 \%$ & $28 \%$ & $51 \%$ \\
\hline
\end{tabular}

Note: When statistical analysis showed that there was no significant difference between the unprotected control specimen and the specimen protected by a UV filter, reduction in fading was reported as $0 \%$.

\section{CONCLUSIONS}

THIS RESEARCH SUPPORTED EARLIER WORK ${ }^{3}$ which showed that some natural dyes were afforded no protection by the essentially colorless filters, i.e., those with a light yellow tint. Controlling level of illumination to the level recommended for textiles (50 lux) is more beneficial than the use of essentially colorless UV filters in protecting some, if not most, natural dyes from fading. UV filters of polyester film with a reflective silver coating are the recommended filtering material when amber-tinted filters distort color objectionably but when greater protection of artifacts is desired than that afforded by filters with very light yellow tints.

The only filters that were significantly altered by 600 AFUs of light exposure were the amber-tinted flexible filters that lightened perceptibly and whose spectral curves were altered. Neither the rigid acrylic nor the other flexible filters were perceptibly altered by 600 AFUs of xenon light exposure. The amber filters would require more careful monitoring and a shorter replacement schedule than the other types of filters. 
for the Reduction of Fading

\section{ACKNOWLEDGEMENTS}

THE AUTHOR THANKS David Clark and Lisa Thorson, research assistants, for their dedicated assistance during the lengthy light exposure and data collection process. SolarScreen and Rohm and Haas provided generous samples of ultraviolet filtering materials. Galvin Glass Inc. (Lincoln, Nebr.) cut all acrylic sheets to specimen size for light exposure. The Agricultural Research Division, University of Nebraska, partially supported this research, which is published as Journal Series Number 8704.

\section{REFERENCES}

1. Adrosko, R. J. Natural Dyes and Home Dyeing. New York: Dover Publications, 1971.

2. American Association of Textile Chemists and Colorists (AATCC). Technical Manual. Research Triangle Park, N.C.: AATCC, 1981-82.

3. Crews, P. C. "A Comparison of Clear Versus Yellow Ultraviolet Filters in Reducing Fading of Selected Dyes." Studies in Conservation33 (1988): 87-93.

4. Hofenk de Graaff, J. H. "Natural Dyestuffs: Origin, Chemical Constitution, and Identification." ICOM Committee for Conservation, 2nd Triennial Meeting Amsterdam, (1969), 69/16/112 pp.

5. Hofenk de Graaff, J. H. “Woven Bouquet: Dyestuff Analysis on a Group of Northern Dutch Flowered Tablecloths and Tapestries of the 17th Century." In ICOM Committee for Conservation, 4th Triennial Meeting. Venice, 1975.75/10/3, 1-15.

6. Hummel, J. J. The Dyeing of Textile Fabrics. London: Cassell, 1888.

7. Launer, H. F., and Black, D. Proceedings of the Fourth International Wool Textile Research Conference. Edited by L.Rebenfeld. Applied Polymer Symposium, No. 18. New York: John Wiley, 1971.

8. Solar Screen Co., 53-11 105th St., Corona, N.Y. 11368, Promotional and technical literature that reports the results of an evaluation of the company's amber-ultraviolet bulb jacket conducted by U.S. Testing Co., Hoboken, N.J.

9. Thomson, G. The Museum Environment. 3d rev. ed.London: Butterworth, 1986.

10. Vigo, T. L., and Wyatt, N. E. "Protection of Light Sensitive Blue Wool Fabric with Cellulose Acetate Films Containing Ultraviolet Stabilizers." In Preservation of Paper and Textiles II. Washington, D.C.: American Chemical Society, 1981.

Journal of the American Institute for Conservation 28 (1989), pp. 117-125

Copyright ( 1989 American Institute for Conservation of Historic and Artistic Works 